\title{
THE LONG-TERM PROGNOSIS OF UNILATERAL PERTHES' DISEASE
}

\author{
E. IPPOLITO, C. TUDISCO, P. FARSETTI \\ From the University of Rome "La Sapienza"
}

\begin{abstract}
We have attempted to identify the most important long-term prognostic factors in Perthes' disease by studying 61 patients affected unilaterally. The average age at diagnosis was 7 years 5 months and at follow-up it was 32 years, an average interval of 25 years. The age at diagnosis, age at follow-up, Catterall group, acetabular coverage, femoral head subluxation and the other head-at-risk signs were statistically correlated with Stulberg, Cooperman and Wallensten (1981) radiographic classes and the Iowa hip score.

Statistically significant correlations were found between Stulberg class and Iowa hip score; age at diagnosis and Stulberg class; age at follow-up and Iowa hip score; and between lateral subluxation of the femoral head and Iowa hip score. Three age-groups of patients were found to carry different long-term prognoses. Those below five years of age at diagnosis showed a statistically significant correlation between Catterall group and Stulberg Classes I and II. Patients between five and nine years of age at diagnosis showed a significant correlation between Catterall group and Stulberg Classes I, II, III and IV while in patients diagnosed after nine years of age there was no statistical correlation between Catterall group and Stulberg class, all having a poor prognosis and ending up in Stulberg Classes III, IV and V.
\end{abstract}

Several long-term follow-up studies of Perthes' disease have been published (Sundt 1949; Evans 1958; Danielsson and Hernborg 1965; Ratliff 1967; Eaton 1967; Gower and Johnston 1971; Brotherton and McKibbin 1977; Mose et al. 1977; O'Hara et al. 1977; Ratliff 1978; Kelly, Canale and Jones 1980; Stulberg, Cooperman and Wallensten 1981; Perpich, McBeath and Kruse 1983; McAndrew and Weinstein 1984). Most emphasise that the two major long-term prognostic factors are the age of the patient at diagnosis and the shape of the femoral head at the end of skeletal growth. However, these conclusions have not been fully supported by use of a standard method of evaluation both at diagnosis and at follow-up and this had made it difficult to evaluate the influence of treatment on the long-term outcome.

Catterall's (1971) radiographic classification has made possible a uniform grading of the disease at its onset, and the identification of five radiographic classes described at the end of skeletal growth by Stulberg et al. (1981) has allowed a reproducible assessment at that stage.

E. Ippolito, Professor of Orthopaedic Surgery

University of Reggio Calabria, Catanzaro, Italy.

C. Tudisco, Assistant Professor

P. Farsetti, Research Doctor

Department of Orthopaedic Surgery, University of Reggio Calabria,

Via S. Brunone di Colonia, Catanzaro, Italy.

Requests for reprints should be sent to Mr E. Ippolito, via Cattaro, 28, 00198 Roma, Italy.

(C) 1987 British Editorial Society of Bone and Joint Surgery $0301-620 \mathrm{X} / 87 / 2021 \$ 2.00$
We have aimed to identify the most important early factors which influence the long-term prognosis of Perthes' disease by studying 61 patients with unilateral involvement whose hips were classified at onset into Catterall grade and, after an average follow-up of 25 years, into Stulberg class.

\section{MATERIALS AND METHODS}

A total of 182 patients were treated for unilateral Perthes' disease at the Department of Orthopaedic Surgery of the University of Rome "La Sapienza" from 1926 to 1977. Of these, 140 had a complete set of both anteroposterior and lateral radiographs from first diagnosis to healing and 105 patients were aged 21 years or more at the time of the study. We were able to trace and evaluate 61 patients both clinically and radiographically, four of them by records and radiographs sent from other hospitals near Rome.

There were 54 men and seven women, and the disease had affected the right hip in 33 patients and the left in 28. At diagnosis, the youngest patient had been 2 years 5 months and the oldest 15 years of age (average 7 years 5 months). At long-term follow-up, ages ranged from 21 to 61 years (average 32 years 2 months). Followup was from 7 to 56 years, averaging 25 years.

On the basis of the earliest radiographs the affected hips were classified according to Catterall (1971) while the head-at-risk signs were also evaluated. Lateral and superior subluxation, and the acetabular coverage, were 
Table I. Results for 61 patients with unilateral Perthes' disease, subdivided into three age groups

\begin{tabular}{|c|c|c|c|c|c|c|c|c|c|c|c|c|}
\hline \multirow[b]{2}{*}{ Case } & \multirow[b]{2}{*}{ Sex } & \multirow[b]{2}{*}{ Side } & \multirow{2}{*}{$\begin{array}{l}\text { Age at } \\
\text { diagnosis }\end{array}$} & \multirow{2}{*}{$\begin{array}{l}\text { Catterall } \\
\text { group }\end{array}$} & \multirow{2}{*}{$\begin{array}{l}\text { Head- } \\
\text { at-risk } \\
\text { signs }\end{array}$} & \multicolumn{3}{|c|}{ Lateral subluxation* } & \multirow{2}{*}{$\begin{array}{l}\text { Age at } \\
\text { follow up } \\
\text { (years) }\end{array}$} & \multirow{2}{*}{$\begin{array}{l}\text { Radiographic } \\
\text { signs of } \\
\text { osteoarthritis }\end{array}$} & \multirow{2}{*}{$\begin{array}{l}\text { Stulberg } \\
\text { class }\end{array}$} & \multirow{2}{*}{$\begin{array}{l}\text { Iowa } \\
\text { score }\end{array}$} \\
\hline & & & & & & Diagnosis & Fragmentation & Healing & & & & \\
\hline 1 & $\mathbf{M}$ & $\mathbf{R}$ & $2 y 5 m$ & 4 & 0 & 100 & 100 & 100 & 22 & No & 2 & 100 \\
\hline 2 & $\mathbf{M}$ & $\mathbf{R}$ & $3 y 4 m$ & 4 & 1 & 80 & 80 & 100 & 29 & No & 2 & 94 \\
\hline 3 & $\mathbf{M}$ & $\mathrm{L}$ & $3 y 5 m$ & 4 & 2 & 100 & 100 & 100 & 21 & No & 1 & 100 \\
\hline 4 & $\mathbf{M}$ & $\mathbf{R}$ & $3 y 8 m$ & 1 & 0 & 87 & 100 & 100 & 28 & No & 1 & 100 \\
\hline 5 & $\mathbf{M}$ & L & $3 y 10 \mathrm{~m}$ & 4 & 1 & 75 & 72 & 100 & 30 & No & 2 & 98 \\
\hline 6 & $\mathbf{M}$ & L & 3y $11 \mathrm{~m}$ & 3 & 1 & 100 & 100 & 100 & 27 & No & 2 & 98 \\
\hline 7 & $\mathbf{M}$ & $\mathbf{R}$ & $4 y$ & 4 & 1 & 75 & 85 & 100 & 35 & No & 2 & 100 \\
\hline 8 & $\mathbf{M}$ & $\mathrm{L}$ & $4 y$ & 4 & 1 & 63 & 100 & 100 & 20 & No & 2 & 98 \\
\hline 9 & $\mathbf{M}$ & $\mathbf{R}$ & $4 y 1 \mathrm{~m}$ & 4 & 1 & 62 & 70 & 77 & 33 & No & 2 & 98 \\
\hline 10 & $\mathrm{~F}$ & $\mathbf{R}$ & $4 y 2 m$ & 2 & 0 & 70 & 81 & 100 & 33 & No & 1 & 100 \\
\hline 11 & $\mathbf{M}$ & $\mathbf{R}$ & 4y $8 \mathrm{~m}$ & 1 & 0 & 77 & 100 & 100 & 24 & No & 1 & 98 \\
\hline 12 & $\mathbf{M}$ & $\mathbf{R}$ & $4 y 8 m$ & 4 & 1 & 80 & 90 & 100 & 21 & No & 2 & 95 \\
\hline 13 & $\mathrm{~F}$ & $\mathbf{L}$ & $5 y 3 \mathrm{~m}$ & 2 & 1 & 100 & 100 & 100 & 24 & No & 2 & 95 \\
\hline 14 & $\mathrm{~F}$ & $\mathbf{R}$ & $5 y 4 \mathrm{~m}$ & 1 & 0 & 100 & 100 & 100 & 24 & No & 1 & 98 \\
\hline 15 & $\mathbf{M}$ & $\mathbf{L}$ & 5y $4 \mathrm{~m}$ & 4 & 1 & 66 & 100 & 100 & 30 & Yes & 4 & 90 \\
\hline 16 & $\mathbf{M}$ & $\mathbf{R}$ & 5y $8 \mathrm{~m}$ & 4 & 3 & 58 & 72 & 100 & 30 & No & 3 & 94 \\
\hline 17 & $\mathbf{M}$ & $\mathbf{R}$ & 5y $9 \mathrm{~m}$ & 4 & 1 & 66 & 72 & 100 & 44 & No & 3 & 99 \\
\hline 18 & $\mathrm{~F}$ & L & $6 y$ & 2 & 2 & 88 & 87 & 100 & 32 & No & 2 & 100 \\
\hline 19 & $\mathbf{M}$ & $\mathbf{R}$ & 6y $1 \mathrm{~m}$ & 2 & 3 & 66 & 72 & 100 & 24 & No & 2 & 97 \\
\hline 20 & $\mathbf{M}$ & $\mathbf{R}$ & 6y $3 \mathrm{~m}$ & 3 & 1 & 87 & 100 & 100 & 29 & No & 3 & 96 \\
\hline 21 & $\mathbf{M}$ & L & 6y $3 \mathrm{~m}$ & 4 & 1 & 77 & 87 & 77 & 24 & No & 3 & 88 \\
\hline 22 & $\mathbf{M}$ & L & $6 y 4 m$ & 4 & 2 & 50 & 50 & 62 & 24 & No & 3 & 75 \\
\hline 23 & $\mathbf{M}$ & $\mathbf{R}$ & 6y $5 \mathrm{~m}$ & 4 & 3 & 69 & 100 & 90 & 32 & No & 2 & 89 \\
\hline 24 & $\mathbf{M}$ & $\mathbf{R}$ & $6 y 6 \mathrm{~m}$ & 4 & 1 & 63 & 100 & 100 & 30 & No & 4 & 85 \\
\hline 25 & $\mathbf{M}$ & $\mathbf{R}$ & 6y $7 \mathrm{~m}$ & 4 & 0 & 70 & 66 & 90 & 26 & No & 3 & 100 \\
\hline 26 & $\mathbf{M}$ & L & 6y $8 \mathrm{~m}$ & 3 & 2 & 72 & 80 & 87 & 34 & No & 3 & 67 \\
\hline 27 & $\mathbf{M}$ & $\mathbf{R}$ & $7 y$ & 3 & 0 & 66 & 80 & 100 & 61 & Yes & 3 & 95 \\
\hline 28 & $\mathbf{M}$ & $\mathbf{R}$ & $7 y 1 \mathrm{~m}$ & 2 & 2 & 75 & 63 & 100 & 35 & No & 1 & 99 \\
\hline 29 & $\mathbf{M}$ & L & $7 y 1 \mathrm{~m}$ & 3 & 1 & 88 & 85 & 85 & 25 & No & 2 & 94 \\
\hline 30 & $\mathbf{F}$ & $\mathbf{R}$ & $7 \mathrm{y} \mathrm{lm}$ & 4 & 2 & 61 & 88 & 75 & 40 & No & 3 & 83 \\
\hline 31 & $\mathbf{M}$ & L & $7 y 2 m$ & 1 & 0 & 75 & 88 & 88 & 27 & No & 1 & 100 \\
\hline 32 & $\mathbf{M}$ & L & $7 y 5 m$ & 3 & 3 & 87 & 75 & 100 & 26 & No & 2 & 94 \\
\hline 33 & $\mathbf{F}$ & $\mathrm{L}$ & $7 y 10 \mathrm{~m}$ & 2 & 2 & 69 & 70 & 77 & 26 & No & 2 & 95 \\
\hline 34 & $\mathbf{M}$ & $\mathbf{L}$ & $7 y 10 \mathrm{~m}$ & 3 & 0 & 81 & 66 & 55 & 50 & Yes & 4 & 59 \\
\hline 35 & $\mathbf{M}$ & L & 8 y $3 \mathrm{~m}$ & 3 & 1 & 58 & 81 & 100 & 37 & No & 3 & 98 \\
\hline 36 & $\mathbf{M}$ & $\mathbf{L}$ & $8 \mathrm{y} 3 \mathrm{~m}$ & 2 & 2 & 66 & 58 & 80 & 22 & No & 1 & 100 \\
\hline 37 & $\mathbf{M}$ & L & $8 y 4 m$ & 3 & 2 & 60 & 53 & 73 & 35 & No & 3 & 94 \\
\hline 38 & $\mathbf{M}$ & L & $8 \mathrm{y} 6 \mathrm{~m}$ & 3 & 3 & 72 & 53 & 80 & 30 & Yes & 4 & 46 \\
\hline 39 & $\mathbf{M}$ & $\mathbf{R}$ & 8 y $9 m$ & 3 & 2 & 80 & 81 & 100 & 38 & No & 3 & 93 \\
\hline 40 & $\mathbf{M}$ & L & 8 y $9 m$ & 2 & 1 & 66 & 77 & 77 & 32 & No & 2 & 90 \\
\hline 41 & $F$ & $\mathbf{R}$ & $8 \mathrm{y} 10 \mathrm{~m}$ & 2 & 2 & 66 & 77 & 85 & 24 & No & 2 & 99 \\
\hline 42 & $\mathbf{M}$ & $\mathrm{L}$ & $9 y$ & 2 & 2 & 72 & 63 & 100 & 27 & No & 4 & 88 \\
\hline 43 & $\mathbf{M}$ & L & $9 y$ & 2 & 0 & 100 & 100 & 100 & 30 & No & 3 & 90 \\
\hline 44 & $\mathbf{M}$ & $\mathbf{R}$ & 9 y $6 \mathrm{~m}$ & 2 & 0 & 61 & 70 & 100 & 33 & No & 3 & 79 \\
\hline 45 & $\mathbf{M}$ & $\mathbf{R}$ & 9 y $7 \mathrm{~m}$ & 4 & 3 & 43 & 75 & 63 & 40 & Yes & 4 & 51 \\
\hline 46 & $\mathbf{M}$ & $\mathbf{R}$ & $9 y 10 \mathrm{~m}$ & 3 & 2 & 61 & 77 & 88 & 38 & Yes & 3 & 67 \\
\hline 47 & $\mathbf{M}$ & L & $10 y$ & 4 & 1 & 70 & 60 & 90 & 43 & Yes & 4 & 90 \\
\hline 48 & $\mathbf{M}$ & $\mathbf{R}$ & $10 \mathrm{y} 10 \mathrm{~m}$ & 2 & 0 & 85 & 100 & 100 & 32 & No & 3 & 75 \\
\hline 49 & $\mathbf{M}$ & L & 11 y $7 \mathrm{~m}$ & 2 & 2 & 47 & 84 & 38 & 33 & No & 3 & 88 \\
\hline 50 & $\mathbf{M}$ & L & 11 y $9 \mathrm{~m}$ & 3 & 0 & 71 & 65 & 70 & 30 & Yes & 3 & 80 \\
\hline 51 & $\mathbf{M}$ & $\mathbf{R}$ & $13 y$ & 2 & 1 & 57 & 55 & 62 & 31 & No & 4 & 87 \\
\hline 52 & $\mathbf{M}$ & $\mathbf{R}$ & $13 y$ & 2 & 2 & 47 & 53 & 100 & 31 & Yes & 4 & 87 \\
\hline 53 & $\mathbf{M}$ & $\mathbf{R}$ & $13 y 3 \mathrm{~m}$ & 2 & 0 & 66 & 66 & 43 & 43 & Yes & 3 & 40 \\
\hline 54 & $\mathbf{M}$ & $\mathbf{R}$ & $13 \mathrm{y} 3 \mathrm{~m}$ & 3 & 1 & 72 & 75 & 100 & 44 & Yes & 3 & 91 \\
\hline 55 & $\mathbf{M}$ & $\mathbf{R}$ & $13 y 5 \mathrm{~m}$ & 2 & 1 & 58 & 100 & 100 & 35 & Yes & 3 & 89 \\
\hline 56 & $\mathbf{M}$ & $\mathbf{R}$ & 13 y $8 \mathrm{~m}$ & 2 & 1 & 75 & 80 & 80 & 21 & Yes & 5 & 87 \\
\hline 57 & $\mathbf{M}$ & $\mathbf{R}$ & $13 \mathrm{y} 11 \mathrm{~m}$ & 3 & 1 & 77 & 66 & 66 & 31 & No & 3 & 81 \\
\hline 58 & $\mathbf{M}$ & $\mathrm{L}$ & $14 y$ & 4 & 0 & 100 & 100 & 100 & 27 & Yes & 3 & 80 \\
\hline 59 & $\mathbf{M}$ & $\mathbf{R}$ & $14 y 3 m$ & 2 & 1 & 70 & 83 & 100 & 48 & Yes & 3 & 55 \\
\hline 60 & $\mathbf{M}$ & L & $14 y 6 \mathrm{~m}$ & 2 & 1 & 100 & 100 & 100 & 56 & Yes & 4 & 30 \\
\hline 61 & $\mathbf{M}$ & L & $15 y$ & 3 & 0 & 81 & 88 & 88 & 50 & Yes & 3 & 50 \\
\hline
\end{tabular}

* Measured at three stages from the most medial part of the femoral head to the acetabulum, and expressed as a percentage of the distance in the unaffected hip 
measured at diagnosis, at the stage of fragmentation and at healing, by the methods described by Stulberg et al. (1981). These have been expressed as a percentage of the measurement on the normal side.

All the patients, regardless of the severity of the disease, had the same treatment. This consisted of short periods of traction in bed at the onset of the disease, then one or two months non-weight-bearing in a hip spica, followed by a hip spica fitted with a weight-relieving caliper. This was applied and then changed every two months until the disease was radiographically healed. The average time of immobilisation in plaster was 23 months.

At late follow-up, a detailed clinical history was taken and a careful physical examination was performed, using the Iowa hip rating score to evaluate function (Larson 1963). The disease was classified according to Stulberg et al. (1981) on the basis of followup radiographs, and signs of osteoarthritis such as sclerosis, femoral or acetabular osteophytes, cysts, and narrowing of the joint space were recorded. All physical examinations and radiographic evaluations were performed by at least two of the authors.

Statistical correlations were made between selected clinical and radiographic features of the disease at its onset and the radiographic and clinical results at followup. The data were subjected to computer analysis, using Pearson's correlation coefficient to assess statistical significance. Pearson's coefficient is statistically significant when its value is $<0.005$ (Hays and Winkler 1971).

\section{RESULTS}

These are presented in detail in Table I.

Diagnosis. At first diagnosis four hips were in the Catterall Group 1, 21 in Group 2, 16 in Group 3 and 20 in Group 4, while from one to three head-at-risk signs were seen in 45 patients. Lateral subluxation of the femoral head was present at diagnosis in 53 patients and was still present at the stage of fragmentation in 44 , whereas at the healing stage only 26 patients still had lateral subluxation, ranging from $38 \%$ to $90 \%$. Superior subluxation of the femoral head was present in nine patients at the healing stage, and was always associated with lateral subluxation. At the healing stage 27 patients showed insufficient acetabular coverage, ranging from $53 \%$ to $84 \%$.

Follow-up. At late review, the lowa hip rating score was 100 points in nine patients, from 99 to 90 in 27 , from 89 to 80 points in 13, and less than 80 in 12 patients. Eight patients were in Stulberg Class I, 17 in Class II, 25 in Class III, 10 in Class IV and one only in Class V. Radiographic signs of osteoarthritis were present in 17 patients, nine of whom were in Stulberg Class III, with an average age of 36 years 3 months. These were $37.5 \%$ of all Class III patients and had an average Iowa hip score of 71.8 points. Seven patients were in Class IV with an
Table II. Correlation between Catterall groups and Stulberg class in three age-groups of patients

\begin{tabular}{|c|c|c|c|c|c|c|c|}
\hline \multirow{2}{*}{$\begin{array}{l}\text { Age } \\
\text { group }\end{array}$} & \multirow{2}{*}{$\begin{array}{l}\text { Catterall } \\
\text { group }\end{array}$} & \multirow{2}{*}{$\begin{array}{l}\text { Number } \\
\text { of hips }\end{array}$} & \multicolumn{5}{|c|}{ Stulberg class } \\
\hline & & & $I$ & II & III & IV & $\mathbf{v}$ \\
\hline \multirow[t]{4}{*}{ Under 5 years } & 1 & 2 & 2 & - & - & - & - \\
\hline & 2 & 1 & 1 & - & - & - & - \\
\hline & 3 & 1 & - & 1 & - & - & - \\
\hline & 4 & 8 & 1 & 7 & - & - & - \\
\hline \multirow[t]{4}{*}{5 to 9 years } & 1 & 2 & 2 & - & - & & - \\
\hline & 2 & 8 & 2 & 6 & - & - & - \\
\hline & 3 & 10 & - & 2 & 6 & 2 & - \\
\hline & 4 & 9 & - & 1 & 6 & 2 & - \\
\hline \multirow[t]{4}{*}{ Over 9 years } & 1 & - & - & - & - & - & - \\
\hline & 2 & 12 & - & - & 7 & 4 & 1 \\
\hline & 3 & 5 & - & - & 5 & - & - \\
\hline & 4 & 3 & - & - & 1 & 2 & - \\
\hline
\end{tabular}

average age of 40 years. These were $70 \%$ of all Class IV patients and had an average lowa score of 64.7 points. The only patient in Class $\mathrm{V}$ was only 21 years old, and scored 87 points on the Iowa hip rating scale.

Hip pain of varying degree was suffered by 29 patients, all with 90 points or less on the Iowa hip scale. Twelve of these patients, all in Stulberg Classes III and IV, showed no radiographic signs of osteoarthritis.

Statistical correlations. The age at diagnosis correlated significantly with both the Iowa hip score at follow-up $(p<0.001)$ and the Stulberg class $(p<0.001)$.

Lateral subluxation of the femoral head at the healing stage correlated with the Iowa hip score at follow-up $(p<0.001)$.

Head-at-risk signs, acetabular coverage, and superior subluxation of the femoral head gave no statistically significant correlation with the Stulberg class or the lowa hip score at follow-up.

The radiographic classes of Stulberg et al. correlated with the Iowa hip score $(\mathrm{p}<0.001)$. The age at follow-up correlated with the Iowa hip rating score at follow-up $(p<0.001)$.

Three groups of patients were identified according to their age at diagnosis, each one with a specific correlation between Catterall's groups and the Stulberg radiographic classes (Table II).

Of 12 patients under five years of age at diagnosis, two who were in Catterall's Group 1 ended up in Stulberg's Class I; one patient was in Group 2 and ended in Class I; one patient was in Group 3 and ended in Class II, while of eight patients in Catterall's Group 4, one ended in Class I (Figs 1 to 4 ) and seven in Class II. A statistically significant correlation was found between Catterall's groups and the first two Stulberg classes $(p=0.002)$. 

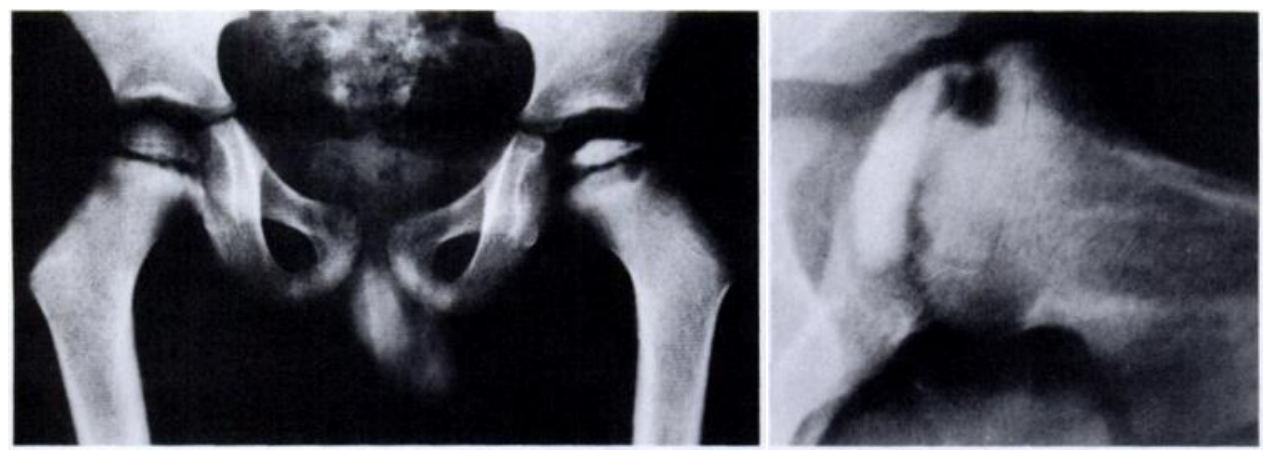

Figs 1 and 2
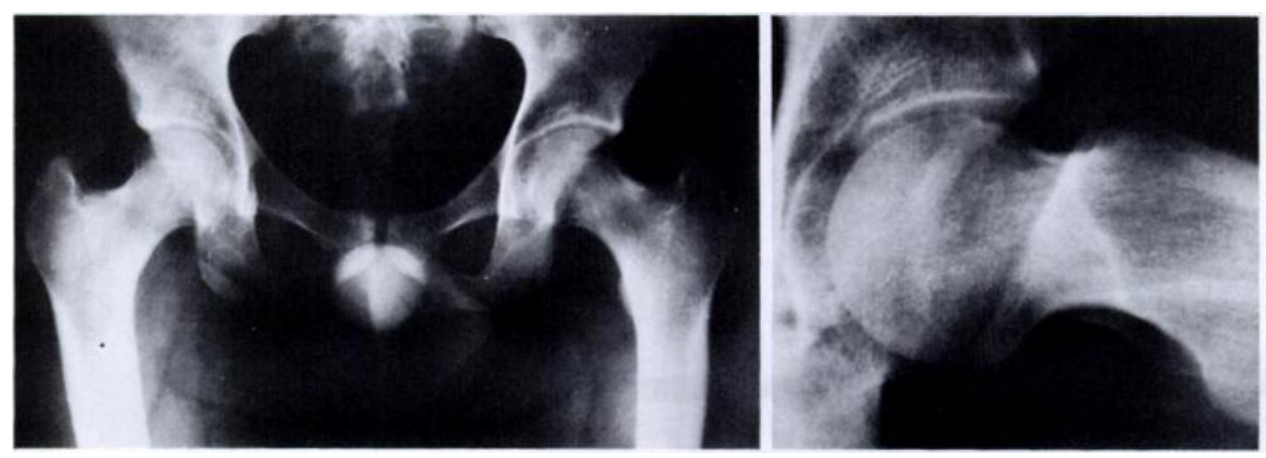

Fig 3 and 4

Case 3. Figures 1 and 2 - Radiographs of a 3.5-year-old boy with left-sided Catterall Group 4 Perthes' disease, showing a large metaphyseal cyst. Figures 3 and 4 - At follow-up when he was 21 years old, the affected hip was in Stulberg Class I and scored 100 points on the Iowa scale.

There were 29 patients between five and nine years of age at diagnosis. Two patients who were in Catterall Group 1 ended in Stulberg Class I. Of the eight Group 2 patients, two ended in Class I and six in Class II. Of the 10 Group 3 patients, two ended in Class II, six in Class III and two in Class IV. Of the nine Group 4 patients, one ended up in Class II, six in Class III and two in Class IV. A statistically significant correlation was found between the Catterall group and the first four Stulberg classes $(\mathrm{p}<0.001)$.

There were 20 patients over nine years of age at diagnosis. Of the 12 who were in Catterall Group 2, seven ended up in Stulberg Class III, four in Class IV and one in Class IV (Fig. 5). The five Group 3 patients ended up in Class III, whereas of the three Group 4 patients, one ended up in Class III and two in Class IV. No statistically significant correlation was found in this age range between Catterall's groups and the radiographic classes of Stulberg et al.

\section{DISCUSSION}

A long-term prognosis for the result of Perthes' disease cannot yet be given during its florid stage. In most previous studies, evaluation has been at the time of follow-up, without correlating the findings with the clinical and radiographic aspects of the disease at its onset, or attempting to find early prognostic indications (Sundt 1949; Evans 1958; Danielsson and Hernborg 1965; Ratliff 1967; Eaton 1967; Gower and Johnston
1971; Mose et al. 1977; Ratliff 1978; Perpich et al. 1983; McAndrew and Weinstein 1984). These studies, though meaningful and important, fail to provide material for a prospective prognosis.

Moreover, the methods of evaluation used in these studies, both at diagnosis and at follow-up, are not uniform and reproducible; this makes comparison of the results very difficult. Mose et al. (1977) used templates with concentric circles to measure the sphericity of the femoral head in an attempt to standardise the anatomical end-results of the disease, but only recently have Stulberg et al. (1981) described five reproducible radiographic classes by which hips affected by Perthes' disease can be assessed at maturity. They showed that congruence between femoral head and acetabulum is as important as the shape of the femoral head alone. Their Classes I and II have the best prognosis because the hip is "spherically congruent"; the incidence of osteoarthritis in joints in these two classes is no greater than that in a normal population. Class III and IV femoral heads are not spherical and "aspherical congruency" leads to deterioration of the affected hip in adult life with the development of osteoarthritis. In Class $\mathbf{V}$ the femoral head is flat and the acetabulum is spherical, and the "aspherical incongruency" causes severe and very early osteoarthritis. In Classes III, IV and V the affected hip deteriorates with increasing age.

In 1971 Catterall published his classic radiographic grouping of Perthes' disease at its onset according to increasing involvement of the femoral head. This 

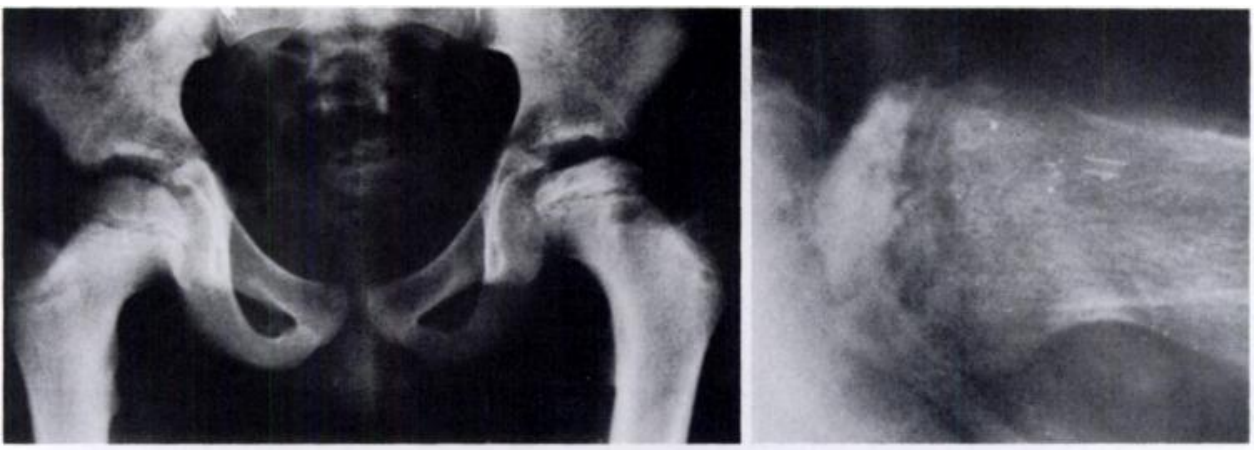

Figs 5 and 6
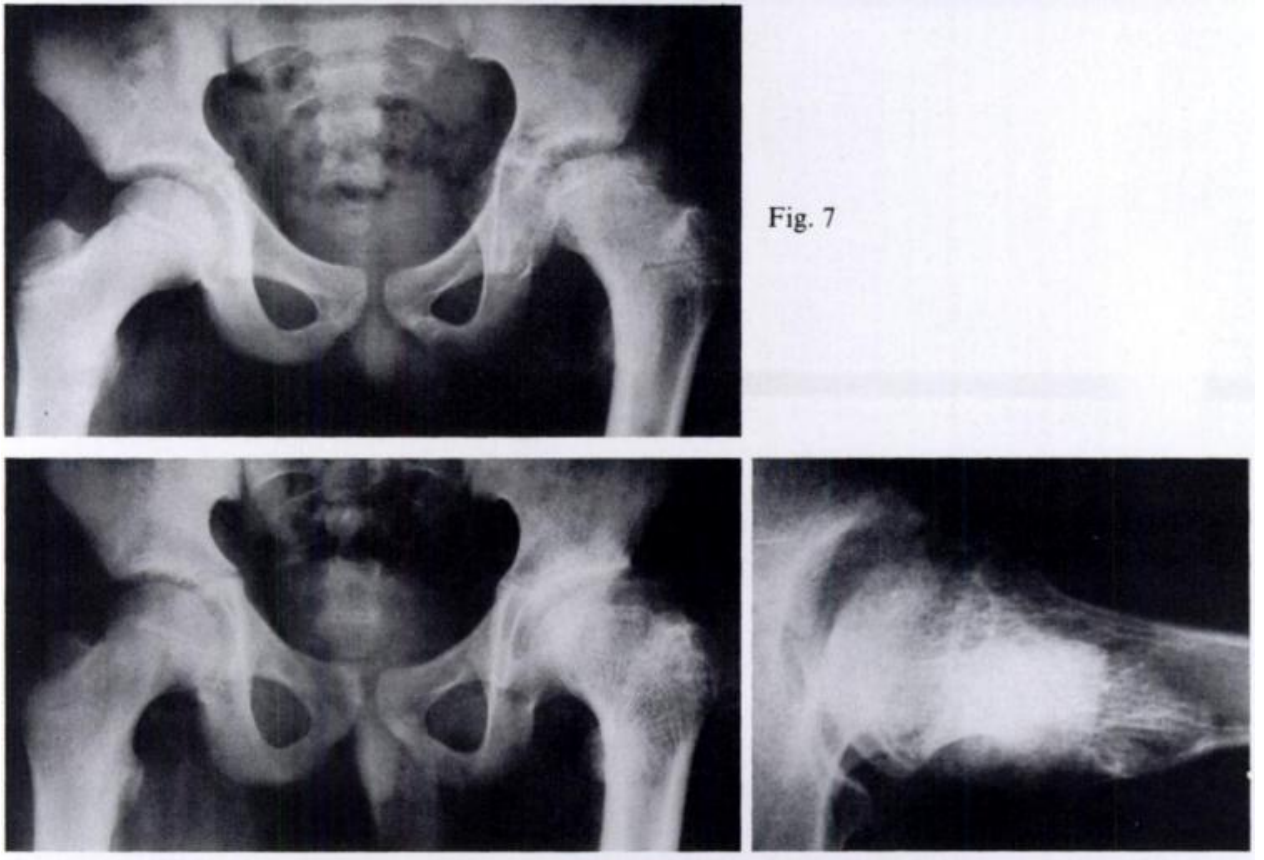

Figs 8 and 9
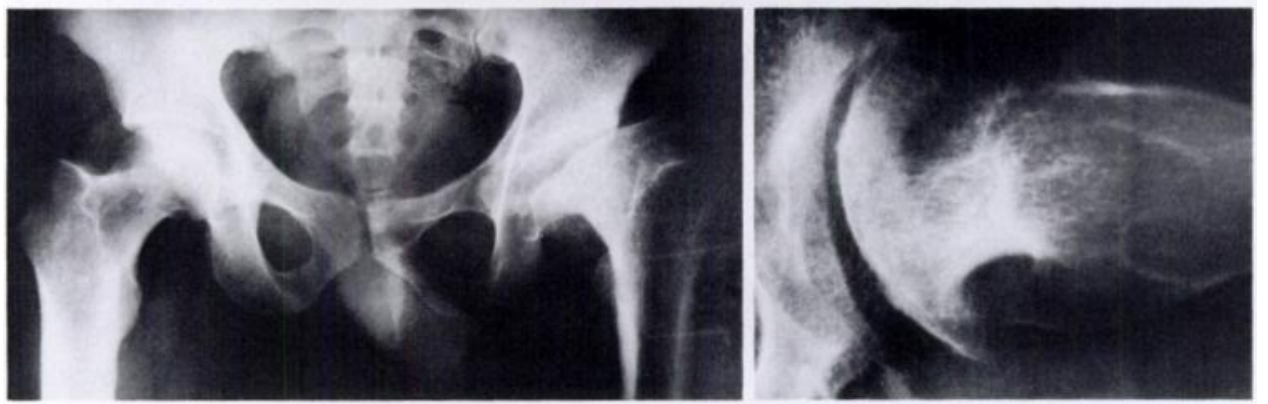

Figs 10 and 11

Case 38. Figures 5 and 6 - Radiographs of an 8.5-year-old boy with left-sided Catterall Group 3 Perthes' disease. The Gage sign, lateral calcification, and both superior and lateral subluxation were present. Figure 7 - Two years later, subluxation had increased and acetabular coverage had decreased. Figures 8 and $9-$ At the age of 14 years, both lateral subluxation of the femoral head and acetabular coverage seemed to have improved slightly but both femoral head and acetabulum are flattened. Figures 10 and $11-$ At follow-up, when the patient was 30 years old, the affected hip was in Stulberg Class IV and scored 46 points on the lowa hip rating scale. Marked lateral and superior subluxation of the femoral head and osteoarthritic changes are seen. The patient was severely disabled.

classification standardises and quantifies the observation made earlier by O'Garra (1959) and by Ponseti and Cotton (1961) that prognosis worsens with the extent of femoral head involvement. However, Catterall provided only short-term follow-up of his patients so that we do not know how these groups manage as adults. Most longterm studies have not used Catterall's grouping either because they were published before it was available or because the lateral radiographs of the affected hip were not available at the time of the study. Uniform and easily reproducible methods of assessment of the disease both at its onset and at follow-up should help elucidate the long-term prognosis of the disease.

In our study, each hip was assigned to a Catterall group at onset, to a Stulberg class at follow-up, and given an Iowa hip score, a precise and reproducible system of 

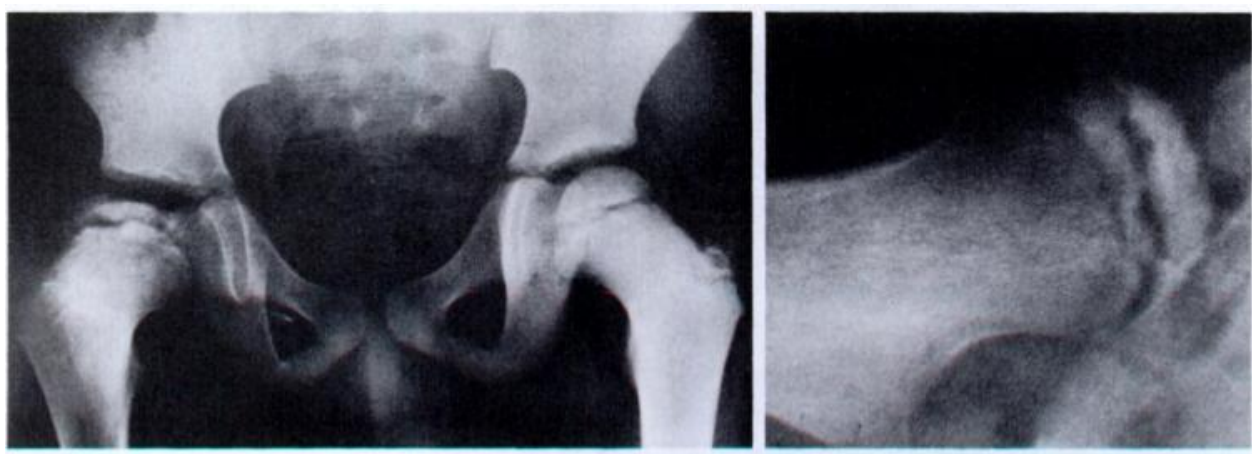

Figs 12 and 13
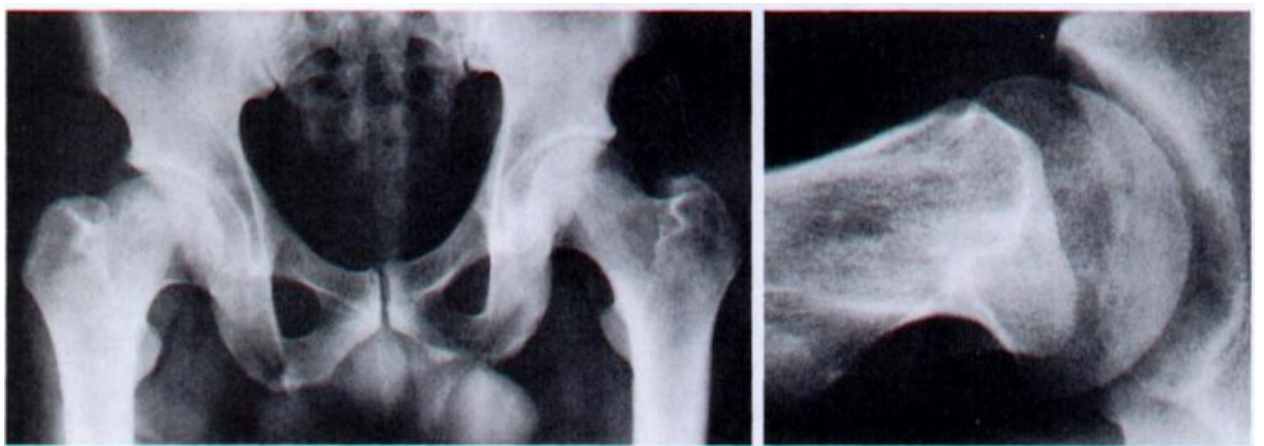

Figs 14 and 15

Case 23. Figures 12 and 13 - Radiographs of a 6.5-year-old boy with right-sided Catterall Group 4 Perthes disease. Lateral calcification, lateral subluxation of the femoral head and reduced acetabular coverage are seen. Figures 14 and 15 - At follow-up, when the patient was 32 years old, the affected hip was in Stulberg Class II and scored 89 points on the lowa scale.
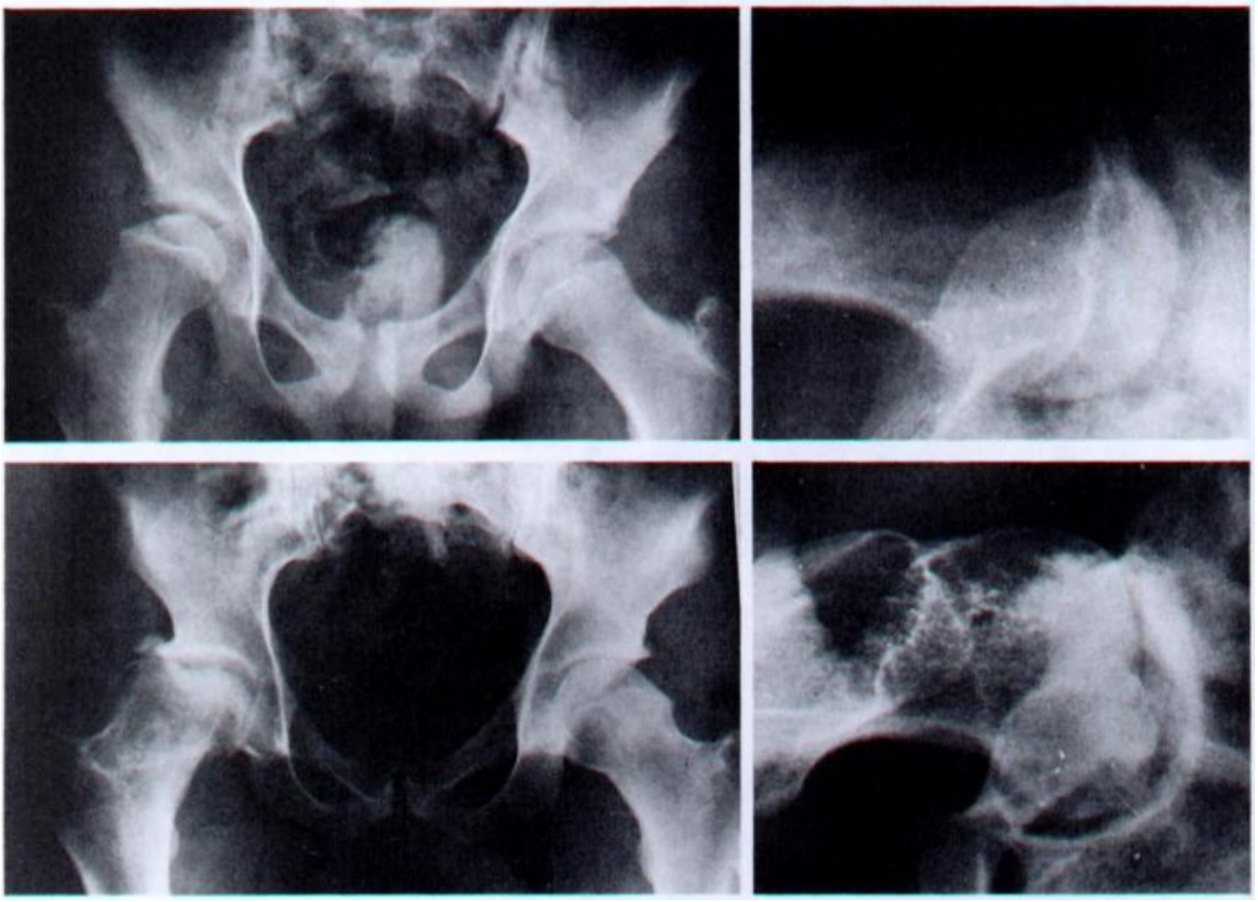

Figs 16 and 17

Case 56. Figures 16 and 17 - Radiographs of a 13.5-year-old boy with right-sided Catterall Group 2 Perthes' disease. Lateral and superior subluxation of the femoral head and reduced acetabular coverage are seen. Figures 18 and 19 - At follow-up, when the patient was 21 years old, the affected hip was in Stulberg Class $V$ and scored 87 points on the lowa scale. Marked osteoarthritis is already present. 
clinical evaluation of the hip. We found a statistically significant correlation between Stulberg class and Iowa score, which seems to indicate that the Stulberg classes have a functional implication. Gower and Johnston (1971) also used the Iowa score and found that in their patients, whose age averaged 44 years, the hips with round femoral heads scored more than those with flattened heads. A similar observation, although using different methods of evaluation, has been made by other authors (Sundt 1949; Danielsson and Hernborg 1965; Eaton 1967; Mose et al. 1977; O'Hara et al. 1977; Kelly et al. 1980; Stulberg et al. 1981; Perpich et al. 1983).

We also found a statistically significant correlation between age at follow-up and lowa score, this being most evident in patients with aspherical femoral heads. For example, in Class III patients the Iowa hip score decreased from 84.2 to 69.6 between the decades from 30 to 40 years and from 40 to 50 years. However, we found that all the hips in the first four Stulberg classes functioned well up to 30 years of age; at that age the difference in the lowa score between spherical and aspherical congruent hips is minimal. After this age hips with aspherical heads tended to deteriorate rapidly with increasing age. McAndrew and Weinstein (1984) reexamined, 12 years later, some of the patients studied by Gower and Johnston (1971), and found that the majority of the hips with flattened femoral heads had worsened markedly from both the radiographic and clinical points of view, whereas hips with spherical femoral heads had maintained about the same Iowa score. Various rates of clinical and radiographic deterioration with age were also reported by Mose et al. (1977), Ratliff (1978) and Stulberg et al. (1981).

We found a statistically significant correlation between age at diagnosis and Stulberg class. This correlation between age at diagnosis and both radiographic and clinical evolution in time has been reported in all previous long-term studies. The general explanation for this finding is that, in the younger patient, the greater growth potential of the femoral head and the acetabulum allows residual deformities to grow out; but there is no general agreement on the age borderline between good and bad prognosis, or on the influence that the degree of involvement of the femoral head at onset may have at any given age on long-term prognosis. We found that under five years of age, even Catterall Group 4 hips ended up in Stulberg Class I or II. Between five and nine years of age, Catterall's classification was the important factor in long-term prognosis; usually Catterall Groups 1 and 2 hips ended up in Stulberg Classes I or II, whereas Groups 3 and 4 ended up in Classes III or IV. There were only three exceptions (Cases 23, 29 and 32 in Table I), and we could not identify any specific clinical or radiographic factors in these cases which could have improved the outcome. We can only speculate that as yet unidentified pathological factors might have had a role (Ponseti et al. 1983). In patients over nine years of age the prognosis was always bad; even Catterall Group 2 hips ended up in Stulberg Classes III, IV or V. These hips also seemed to deteriorate at an earlier age than hips in the same Stulberg class which had been affected at a younger age.

McAndrew and Weinstein (1984) found that the age borderline between good and bad long-term prognosis was eight years, but they were unable to make any correlation with Catterall grouping. O'Hara et al. (1977) found an age borderline of five years, and they also found that Catterall Groups 1 and 2 hips developed spherical femoral heads more often than Groups 3 and 4, but they did not correlate Catterall grouping with specific agegroups when they gave their long-term results. Similar observations were made by Kelly et al. (1980) using an age borderline of six years. Stulberg et al. (1981) found that several hips in Catterall Groups 3 and 4 ended up in Class II and vice-versa, namely that some Catterall Group 2 hips ended up in Classes III or IV; however, they did not provide a correlation with age at diagnosis and, moreover, they had 14 patients in Class V, most of whom were older than nine years of age at diagnosis and had been in Catterall Group 2. We had 20 patients older than nine years at diagnosis, 12 of them in Catterall's Group 2, but only one ended up in Class V. It is possible that the different treatment provided in the two series could account for this difference.

In the entire series, neither the number of head-atrisk signs nor the acetabular coverage correlated with the Stulberg class or the the Iowa score. Lateral subluxation of the femoral head at the end of the florid stage of the disease was the only head-at-risk sign which correlated with the adult function of the hip, but lateral subluxation was statistically significant only when it was still present at the healing stage of the disease. In several hips subluxation at diagnosis or at the stage of fragmentation recovered completely during healing. Other authors have reported that lateral subluxation negatively influences the long-term prognosis of the disease, but they did not make clear at which stage of the disease the measurements were taken (O'Hara et al. 1977; Ratliff 1978; Stulberg et al. 1981).

Osteoarthritis had developed in $37 \%$ of our Class III patients and in $70 \%$ of Class IV and it was already present at the ages of 30 and 40 years, whereas the only Class $\mathrm{V}$ patient in our series had moderate pain on prolonged weight-bearing or sporting activity before he was 20 years of age. He had marked radiographic osteoarthritis at 21 years of age. No patient in Class I or II had osteoarthritis. Mose et al. (1977) found that in their 25- and 35-year-old age-groups the incidence of osteoarthritis was respectively $25 \%$ and $31 \%$, with the maximum incidence in those with irregular femoral heads. Stulberg et al. (1981) found that only Class V patients always developed early osteoarthritis, whereas Class III and IV patients started to develop osteoarthritis in their 40s and 50s. In our series, Class III and IV 
patients started to develop osteoarthritis at least 10 years earlier. This different long-term behaviour between our patients and those of Stulberg et al. could be related either to the different treatment given or to the older age at onset of our Class III and IV patients.

A varying degree of hip pain, in the absence of radiographic signs of osteoarthritis, was present in several patients who scored less than 90 points on the Iowa scale; these patients often started to complain of pain during their adolescence. This observation has also been made by Clarke and Harrison (1983) and by McAndrew and Weinstein (1984). Although we do not know the specific cause of pain in these patients, it is possible that articular incongruence not identifiable on standard radiographs could be responsible.

In previous long-term follow-up series the influence of treatment on results is difficult to assess, either because treatment differs between patients in the same series or because the severity of the disease at diagnosis is not indicated. The patients in our series had uniform treatment and our results can be compared with those of the second study-group of Stulberg et al. (1981). Their patients were classified at diagnosis to a Catterall group and also had uniform treatment, which included short periods of bed rest followed by walking on crutches without weight-bearing. It seems possible that our treatment helped to prevent the development of Stulberg Class V results in our patients who were over nine years of age at diagnosis. All but one of these patients ended with a Class III or IV hip, so that osteoarthritis started to develop later in life than in the Class V patients of the Stulberg series. On the other hand, if we compare these patients with the Class III and IV results in the Stulberg series, osteoarthritis developed at an earlier age in our patients. It is difficult to establish whether the earlier deterioration of the hips in our Class III and IV patients is due to the treatment or to the older age of the patients at diagnosis.

Brotherton and McKibbin's (1977) long-term study deserves particular mention in this respect. They reviewed, with an average follow-up of 17 years, 87 patients treated by long periods of recumbency in bed with the legs in wide abduction, first in traction and later in plaster casts. On Ratliff's (1967) rating system, none of their four patients in Catterall Group 4 older than five years at diagnosis had a bad result; three were fair and one was good. In our Group 4 patients, of nine between five and nine years of age at diagnosis one patient ended in Class II and six in Class III. Unfortunately, no comparison of the degree of sphericity of the femoral head is possible since Ratliff's grading system allows a "normal or slightly flattened" femoral head in a good result.
We wish to thank Dr Mirella Schaerf, head of the Centro Interdipartimentale per il Calcolo Scientifico dell'Università di Roma "La Sapienza", for her assistance with the statistical analysis. We thank Professor Nazario Basile and Dr Ivan Liguori for their cooperation and help in assessing four of our patients. We also thank $\mathrm{Mr}$ Giuseppe Pastres for helping us in tracking down the old records of our patients and Mr Mario Termine for the photographic work. Thanks are also due to Miss Lucy Kerr for revising the English translation of the manuscript. Lastly, thanks are due to General Giuseppe Tudisco for his contribution in locating several of the patients.

\section{REFERENCES}

Brotherton BJ, McKibbin B. Perthes' disease treated by prolonged recumbency and femoral head containment: a long-term appraisal. J Bone Joint Surg [Br] 1977;59-B:8-14.

Catterall A. The natural history of Perthes' disease. J Bone Joint Surg [Br] 1971 ;53-B:37-53.

Clarke NMP, Harrison MHM. Painful sequelae of coxa plana. J Bone Joint Surg [Am] 1983;65-A:13-8.

Danielsson LG, Hernborg J. Late results of Perthes' disease. Acta Orthop Scand 1965;36:70-81.

Eaton GO. Long-term results of treatment in coxa plana: a follow-up study of eighty-eight patients. J Bone Joint Surg [Am] 1967;49-A : 1031-42.

Evans DL. Legg-Calvé-Perthes' disease : a study of late results. J Bone Joint Surg [Br] 1958;40-B:168-81.

Gower WE, Johnston RC. Legg-Perthes disease : long-term follow-up of thirty-six patients. J Bone Joint Surg [Am] 1971;53-A :759-68.

Hays LW, Winkler RL. Statistics: probability, inference, and decision. New York etc: Holt, Rinehart and Winston, 1971.

Kelly FB Jr, Canale ST, Jones RR. Legg-Calvé-Perthes disease: longterm evaluation of non-containment treatment. J Bone Joint Surg [Am] 1980;62-A :400-7.

Larson CB. Rating scale for hip disabilities. Clin Orthop 1963;31:85-93.

McAndrew MP, Weinstein SL. A long-term follow-up of Legg-CalvéPerthes disease. J Bone Joint Surg [Am] 1984;66-A :860-9.

Mose K, Hjorth L, Ulfeldt M, Christensen ER, Jensen A. Legg-CalvèPerthes disease: the late occurrence of coxarthrosis. Acta Orthop Scand 1977; Suppl 169.

O'Garra JA. The radiographic changes in Perthes' disease. J Bone Joint Surg $[B r] 1959 ; 41-B: 465-76$.

O'Hara JP, Davis ND, Gage JR, Sundberg AB, Winter RB. Long-term follow-up of Perthes' disease treated nonoperatively. Clin Orthop 1977;125:49-56.

Perpich M, McBeath A, Kruse D. Long-term follow-up of Perthes' disease treated with spica casts. J Pediatr Orthop 1983;3:160-5.

Ponseti IV, Cotton RL. Legg-Calvé-Perthes disease: pathogenesis and evolution. J Bone Joint Surg [Am] $1961 ; 43-A: 261-74$.

Ponseti IV, Maynard JA, Weinstein SL, Ippolito EG, Pous JG. LeggCalvé-Perthes disease: histochemical and ultrastructural observations of the epiphyseal cartilage and physis. J Bone Joint Surg [Am] 1983;65-A:797-807.

Ratliff AHC. Perthes' disease: a study of thirty-four hips observed for thirty years. J Bone Joint Surg [Br] 1967;49-B:102-7.

Ratliff AHC. Perthes' disease. Part II. The long-term results. In : LloydRoberts GC, Ratliff AHC. Hip disorders in children. London: Butterworths, 1978:150-64.

Stulberg SD, Cooperman DR, Wallensten $\mathbf{R}$. The natural history of Legg-Calvé-Perthes disease. J Bone Joint Surg [Am] $1981 ; 63-A$ : $1095-1108$.

Sundt H. Further investigations respecting malum coxae Legg-CalvéPerthes with special regard to the prognosis and treatment. Acta Chir Scand 1949; Suppl 148. 